\title{
Congenital heart defects in CHARGE: The molecular role of CHD7 and effects on cardiac phenotype and clinical outcomes
}

\author{
Joshua K. Meisner $^{1}$ | Donna M. Martin ${ }^{1,2}$ (
}

${ }^{1}$ Department of Pediatrics, University of Michigan, Ann Arbor, Michigan

${ }^{2}$ Department of Human Genetics, University of Michigan, Ann Arbor, Michigan

\section{Correspondence}

Donna M. Martin, Department of Pediatrics, University of Michigan, 1150 W. Medical Center Dr., 8220C MSRB III, Ann Arbor, MI 48109-5652.

Email: donnamm@umich.edu

Funding information

National Institutes of Health, Grant/Award Number: R01-014456

\begin{abstract}
CHARGE syndrome is characterized by a pattern of congenital anomalies (Coloboma of the eye, Heart defects, Atresia of the choanae, Retardation of growth, Genital abnormalities, and Ear abnormalities). De novo mutations of chromodomain helicase DNA binding protein 7 (CHD7) are the primary cause of CHARGE syndrome. The clinical phenotype is highly variable including a wide spectrum of congenital heart defects. Here, we review the range of congenital heart defects and the molecular effects of CHD7 on cardiovascular development that lead to an over-representation of atrioventricular septal, conotruncal, and aortic arch defects in CHARGE syndrome. Further, we review the overlap of cardiovascular and noncardiovascular comorbidities present in CHARGE and their impact on the peri-operative morbidity and mortality in individuals with CHARGE syndrome.
\end{abstract}

KEYWORDS

CHARGE, CHD7, congenital heart defects

\section{1 | INTRODUCTION}

CHARGE syndrome is a rare genetic disorder (OMIM 214800) with an estimated incidence of approximately 1 in 10,000 (Issekutz, Graham, Prasad, Smith, \& Blake, 2005). CHARGE syndrome was initially described as a pattern of anomalies by Hall (1979) and Hittner, Hirsch, Kreh, and Rudolph (1979) that was formally defined as an association by (Pagon, Graham, Zonana, \& Yong, 1981). The primary features of CHARGE-ocular coloboma $(C)$, heart malformations $(H)$, atresia of the choanae $(A)$, retardation of growth $(R)$, genital hypoplasia $(G)$, and ear abnormalities $(E)$-form an acronym that serves as the name of the condition. CHARGE was subsequently defined as a syndrome with the identification of autosomal dominant pathogenic variants in the CHD7 gene in 2004 (Vissers et al., 2004), which occurs in 58-90\% of patients with CHARGE syndrome (Jongmans et al., 2006; Lalani et al., 2006; Legendre et al., 2017; Zentner, Layman, Martin, \& Scacheri, 2010). An additional spectrum of single gene pathogenic variants have been identified in individuals with the clinical features of CHARGE (Moccia et al., 2018).

Since the identification of CHD7 and further refinement of specific features of inner ear formation, diagnostic criteria for the syndrome have undergone multiple revisions (Blake et al., 1998; Hale, Niederriter, Green, \& Martin, 2016; Sanlaville \& Verloes, 2007; Verloes, 2005). Heart malformations remain a key criterion for the definitions of the syndrome. While there is a highly variable cardiac phenotype, cardiac defects convey significant implications for the clinical course of individuals with CHARGE syndrome. In this review, we will discuss the spectrum of congenital heart disease in CHARGE syndrome, the clinical impact of CHARGE syndrome on outcomes in congenital heart disease, and our current understanding of the mechanisms of action of CHARGE syndrome in cardiac development.

\section{2 | PATTERNS OF CONGENITAL HEART DISEASE IN CHARGE}

\subsection{Types of congenital heart disease in CHARGE}

The spectrum of congenital heart disease is highly variable in CHARGE syndrome and encompasses mild cardiac malformations (e.g., patent ductus arteriosus [PDA] and atrial septal defects) that may not require intervention to more severe malformations 
(e.g., Tetralogy of Fallot) that require cardiothoracic surgery in infancy. Conotruncal defects (31-42\%) and atrioventricular septal defects (AVSDs; 13-17\%) with associated or isolated PDA and aortic arch abnormalities are seen more frequently in individuals with CHARGE than the full population of patients with congenital heart disease (Corsten-Janssen, Kerstjens-Frederikse, et al., 2013; Corsten-Janssen, Saitta, et al., 2013; Corsten-Janssen, van Ravenswaaij-Arts, \& Kapusta, 2016; Lin, Chin, Devine, Park, \& Zackai, 1987; Vissers et al., 2004; Wyse, Al-Mahdawi, Burn, \& Blake, 1993).

We characterized this further by compiling all large case series/ cohort studies (>4 patients) with published detail sufficient for classification of congenital heart disease types and compared these to the largest meta-analysis to date of all congenital cardiac defects (Table 1; Liu, Chen, et al., 2019). The cardiac phenotypes across these studies were arranged according to the large classifications based off embryologic development using a modified classification system from Botto et al. (2007). The largest single study of individuals with CHARGE syndrome examining the spectrum of congenital heart defects included 299 individuals with CHARGE syndrome (Corsten-Janssen, KerstjensFrederikse, et al., 2013; Corsten-Janssen, Saitta, et al., 2013). This large study aligns well with the data found in the composite of the additional studies (Table 1) and demonstrates the over-representation of conotruncal defects and AVSDs (Figure 1). Often overlapping within these larger classification categories is a high incidence of aortic arch abnormalities (e.g., right aortic arch and aberrant right subclavian arteries) and additional presence of a PDA (CorstenJanssen et al., 2016). Despite this bias toward conotruncal and AVSD defects, the incidence of CHARGE syndrome remains rare enough that specifically screening for CHARGE in patients with heart defects plus an additionally involved organ system is not cost-effective (Corsten-Janssen et al., 2014; Corsten-Janssen \& Scambler, 2017).

Given the range of pathogenic variants seen in CHARGE syndrome (Moccia et al., 2018; Zentner et al., 2010), it is important to understand the impact of causative CHD7 variants on the CHARGE syndrome

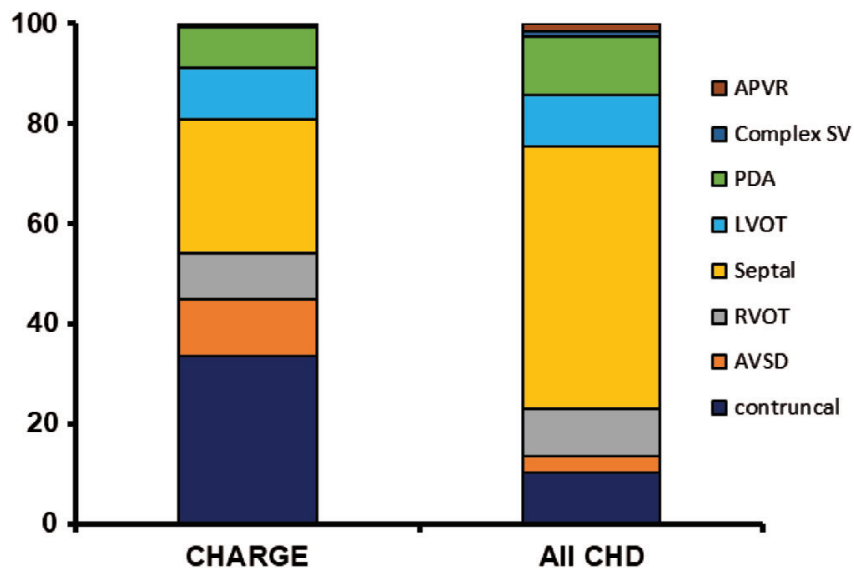

FIGURE 1 Spectrum of congenital heart disease in CHARGE syndrome compared to all congenital heart disease. Conotruncal defects and atrioventricular septal defects (AVSDs) are overrepresented in CHARGE compared to all congenital heart disease from Table 1. There are fewer isolated septal defects, similar degree right ventricular outflow tract (RVOT), left ventricular outflow tract (LVOT), isolated patent ductus arteriosus (PDA), complex single ventricles (SV), and anomalous pulmonary venous return (APVR)

TAB LE 1 Spectrum of congenital heart disease in CHARGE syndrome versus all congenital heart disease

\begin{tabular}{|c|c|c|c|c|c|c|}
\hline \multirow[b]{2}{*}{$\begin{array}{l}\text { Primary classification (modified from } \\
\text { Botto, Lin, Riehle-Colarusso, Malik, \& } \\
\text { Correa, 2007) }\end{array}$} & \multicolumn{4}{|l|}{ CHARGE syndrome } & \multicolumn{2}{|l|}{ All CHD } \\
\hline & $\begin{array}{l}\text { Literature review } \\
\text { (\# patients) }\end{array}$ & $\begin{array}{l}\text { Corsten-Janssen et al., } \\
2013 \text { (\# patients) }\end{array}$ & $\begin{array}{l}\text { Total (\# } \\
\text { patients) }\end{array}$ & $\begin{array}{l}\% \text { of } \\
\text { all CHD }\end{array}$ & $\begin{array}{l}\text { Prevalence } \\
\text { per } 1,000\end{array}$ & $\begin{array}{l}\% \text { of } \\
\text { all CHD }\end{array}$ \\
\hline Conotruncal & 88 & 54 & 142 & 33.6 & 0.876 & 10.2 \\
\hline Atrioventricular Septal defect & 22 & 26 & 48 & 11.3 & 0.290 & 3.4 \\
\hline Septal defect & 55 & 58 & 113 & 26.7 & 4.512 & 52.4 \\
\hline $\begin{array}{l}\text { Left ventricular outflow tract } \\
\text { malformation }\end{array}$ & 20 & 23 & 43 & 10.2 & 0.886 & 10.3 \\
\hline PDA & 15 & 19 & 34 & 8.0 & 1.004 & 11.7 \\
\hline
\end{tabular}

Note. All congenital heart disease data adapted from Liu, Chen, et al. (2019) with meta-analysis across nations and time eras, encompassing 130,758,851 births with congenital heart disease from 1970 to 2017 . Congenital heart disease from literature review of all studies $>4$ CHARGE patients with sufficient congenital heart disease description to enable classification and with comparison of largest single study by Corsten-Janssen, Kerstjens-Frederikse, et al. (2013) and Corsten-Janssen, Saitta, et al. (2013). (Aramaki et al., 2006; Blake, Russell-Eggitt, Morgan, Ratcliffe, \& Wyse, 1990; Busa et al., 2016; Corsten-Janssen, Kerstjens-Frederikse, et al., 2013; Corsten-Janssen, Saitta, et al., 2013; Cyran, Martinez, Daniels, Dignan, \& Kaplan, 1987; Gennery et al., 2008; Jongmans et al., 2006; Jongmans et al., 2008; Legendre et al., 2012; Lin et al., 1987; Oley, Baraitser, \& Grant, 1988; Strömland et al., 2005; Wyse et al., 1993). 
cardiac phenotype. Within the spectrum of CHD in CHARGE syndrome, there appears to be no significant difference in presence of $\mathrm{CHD}$ in patients with or without a CHD7 pathogenic variant (Bergman et al., 2011; Corsten-Janssen, Kerstjens-Frederikse, et al., 2013; CorstenJanssen, Saitta, et al., 2013; Hale et al., 2016; Legendre et al., 2017; Vissers et al., 2004; Zentner et al., 2010). However, some larger series suggest an increase in congenital heart disease in CHD7-positive patients (66-92\%) compared to $71 \%$ of $C H D 7-$ negative patients (Jongmans et al., 2006; Jyonouchi, McDonald-McGinn, Bale, Zackai, \& Sullivan, 2009; Lalani et al., 2006). Lanali et al. also suggests a higher incidence of AVSD and PDA in isolation or associated with other lesions in CHARGE patients with CHD7 pathogenic variants.

For individuals with CHD7-related CHARGE syndrome, the type of variant in CHD7 had a genotype-phenotype relationship with more severe phenotypes being associated with truncating variants (Bergman et al., 2011; Legendre et al., 2017). This includes an increased burden of congenital heart disease in CHARGE syndrome which occurs in $70-82 \%$ of individuals with a truncating $\mathrm{CHD7}$ variant compared to $22-64 \%$ in individuals with nontruncating variants (Corsten-Janssen, Kerstjens-Frederikse, et al., 2013; Corsten-Janssen, Saitta, et al., 2013; Legendre et al., 2017). The primary limitation of these data to detect more detailed genotype-phenotype relationships is the sample size in individual studies. The growing repository of large cohort studies that collect the cardiac phenotype and presence of CHD7 variant or CHD7 variant type (truncating or nontruncating; Corsten-Janssen, Kerstjens-Frederikse, et al., 2013; Corsten-Janssen,
Saitta, et al., 2013; Jongmans et al., 2006; Lalani et al., 2006; Legendre et al., 2017; Vissers et al., 2004; Wincent et al., 2008) should allow for pooling of these large datasets for more detailed meta-analysis. However, the overlap of pathogenic variant data and congenital heart defect phenotype is not routinely presented in most studies, which prevents data aggregation and meta-analysis and argues for publication of supplemental datasets including this information.

\section{2 | Mechanisms of cardiac malformations in CHARGE syndrome}

\subsection{1 | Cardiac development}

The heart is the first organ to develop during embryogenesis. It proceeds primarily from the splanchnic mesoderm, though the endoderm and ectoderm also play important contributions. The mesoderm forms the first recognizable heart structure, the primitive heart tube, during gastrulation. The primitive heart tube forms the first and second heart fields, with the first heart field forming the inlets (atrioventricular valves and atria), left ventricle, and connections to the systemic and pulmonary venous pathways (Figure 2a). The second heart field forms the right ventricle and outflow tract which is initially a single vessel that then septates into the great arteries with formation of the conal septum (Verzi, McCulley, De Val, Dodou, \& Black, 2005). The outflow (truncus arteriosus) connects to the dorsal aortae through the (a)

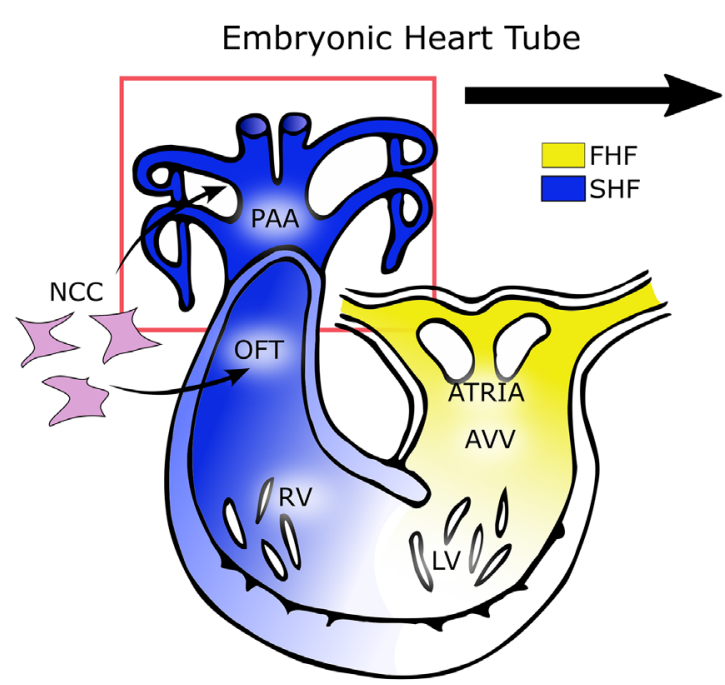

(b)

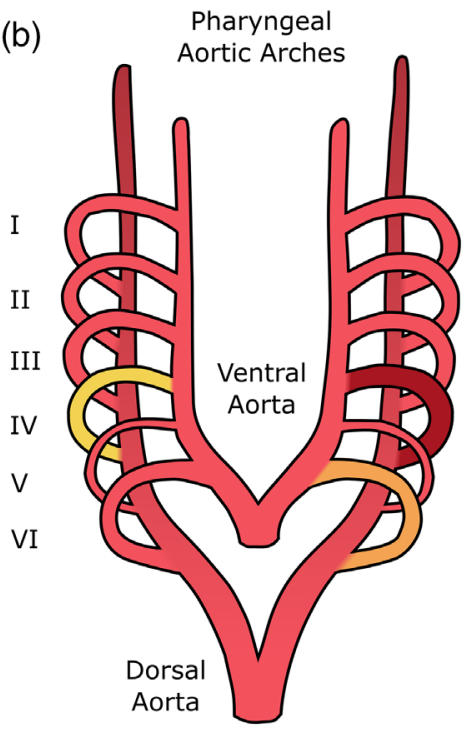

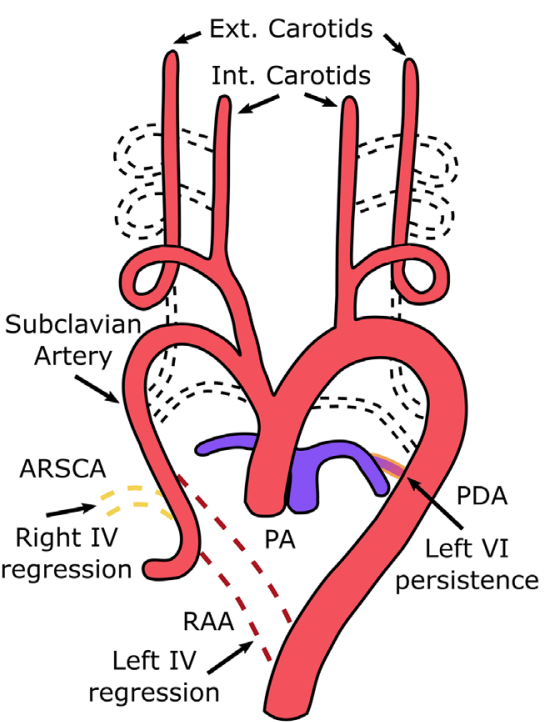

Normal Development

FIGURE 2 Stages of cardiac development. (a) Looping of first and second heart fields demonstrating migration of neural crest cells (NCC) to the conotruncal out flow tract (OFT) and pharyngeal aortic arches (PAA). Incomplete looping in the right ventricle (RV) or septation of the outflow tracts results in double outlet right ventricle or other conotruncal defects (e.g., Tetralology of Fallot, transposition of the great arteries). Incomplete left ventricular (LV) looping results in a double inlet left ventricle and is less common in CHARGE. Atrioventricular valve formation (AVV) begins in the first heart field (FHF) with additional components from the secondary heart field (SHF). (b) Aortic arch development. Regression in the aortic arches is heavily influenced by NCCs. Abnormal arch regression can lead to aortic arch defects typically seen in CHARGE. Examples include persistence of the left $\mathrm{VI}$ arch (i.e., patent ductus arteriosus (PDA), regression of the left IV arch leading to development of the right IV arch and a right aortic arch, and regression of the right IV arch leading to an aberrant right subclavian artery (ARSCA) 
pharyngeal arch arteries (Figure 2b). The heart fields rotate and expand in size to establish heart looping with the second heart field moving anterior and rightward.

A complex series of events orchestrates the septation of the looped heart into four chambers with parts of both the first and second heart field contributing to the intraventricular septum. As the first and second heart field loop, the atria and ventricles are brought together at the crux of the heart, where the endocardium undergoes endothelial to mesenchymal transition, resulting in swelling and formation of the endocardial cushions. The cushions then remodel to form the atrioventricular valves. Incomplete anterior-posterior cushion union results in lack of septation of the atrioventricular valves (i.e., AVSD).

A similar process of cushion formation and rotation occurs at the level of the outlet to form the great arteries and aortic and pulmonary valves. Outflow tract cushion formation is dependent on migration of neuroectodermally derived cells called cardiac neural crest cells (see reviews [Plein, Fantin, \& Ruhrberg, 2015; Stoller \& Epstein, 2005]). Alteration of cardiac neural crest cell function can result in abnormal rotation (i.e., transposition of the great arteries), lack of outflow tract cushion development (i.e., truncus arteriosus), or abnormal positioning (e.g., anterior mal-alignment which results in Tetralogy of Fallot) and lead to specific patterns of congenital heart defects. Neural crest cells similarly play a critical role in regression and development of the pharyngeal arches and arch arteries (see review [Plein et al., 2015]).

It is useful to consider the spectrum of congenital heart disease as arising from patterns of altered migration (e.g., malalignment of the conal septum leading to Tetralogy of Fallot), incomplete growth (e.g., AVSD, VSD, or ASD), inappropriate regression (e.g., aberrant subclavian arteries or right aortic arch), or lack of appropriate regression (e.g., PDA) (Figure 2b). As such, impaired development within the first and second heart fields leads to the association of right sided heart lesions with conoventricular (outlets and conal septum) defects (e.g., Tetralogy of Fallot, truncus arteriosus, double outlet right ventricle) and association of the left ventricle with inlet abnormalities (e.g., double inlet left ventricle) (Figure 2a).

Given the increased frequency of conoventricular and arch vessel defects in CHARGE syndrome and the critical role in neural crest cells in septation of the outflow tract and conal septum and the pharyngeal arches, there has been long-standing focus of the involvement of neural crest cells in CHARGE syndrome (Siebert, Graham, \& MacDonald, 1985). However, as demonstrated by the overrepresentation of AVSD in CHARGE syndrome and nonessential role of neural crest cells in endocardial cushion formation, additional mechanisms are likely involved in congenital heart defects associated with CHARGE syndrome.

\subsection{2 | CHD7 and associated genes in cardiac development}

Chromodomain helicase DNA binding protein 7 (CHD7, OMIM 608892) and downstream genes are the primary causes of CHARGE syndrome. CHD7 encodes an ATP-dependent chromatin modifier that associates with all three forms of methylated H3K4 (Schnetz et al.,
2009). As with chromatin modifiers and epigenetic mechanisms of cardiac development, CHD7 is broadly expressed in tissues, which helps to explain its pleiotropic effects.

As suggested by the pattern of cardiac defects and embryology, there are multiple lines of evidence showing that $\mathrm{CHD} 7$ plays a critical role in neural crest cell development and presents a stereotypic example of a neurocristopathy (Pauli, Bajpai, \& Borchers, 2017). CHD7 is known to cooperate with PBAF to control formation of neural crest cells (Bajpai et al., 2010) and partially regulates Sox10 deregulation in the neural crest cells (Asad et al., 2016) leading to the CHARGE phenotype. Downstream Semaphorin and Robo pathways are critical to neural crest development and migration and may be involved in CHD7negative CHARGE syndrome (S R Lalani et al., 2004; Liu, Guo, et al., 2019; Schulz et al., 2014; Ufartes et al., 2018). Additionally, there is also evidence that the disruption of Fam172a, which interacts with CHD7 and Argo2, can affect alternative splicing in neural crest cells and lead to a CHARGE phenotype (Bélanger et al., 2018), with neural crest cells being particularly sensitive to disruption of splicing machinery (BérubéSimard \& Pilon, 2019). However, not all aspects of CHARGE can be related to the role of CHD7 on neural crest development. CHD7 is additionally expressed in the mesoderm of the developing heart. Mesoderm lineage-specific ablation (Mesp1) of CHD7 leads to disruption of endocardial cushion formation, which may explain the overrepresentation of AVSD defects in CHARGE syndrome (Payne et al., 2015).

It has been long recognized that there is a clinical overlap between individuals with CHARGE syndrome and DiGeorge Sequence/22q11.2 microdeletion syndrome (22q11.2 DS) (Corsten-Janssen, KerstjensFrederikse, et al., 2013; Corsten-Janssen, Saitta, et al., 2013; Randall et al., 2009; Sanka, Tangsinmankong, Loscalzo, Sleasman, \& Dorsey, 2007). CHD7 and TBX1 (the locus associated with 22q11.2 DS specific cardiac defects [Lindsay et al., 2001; Merscher et al., 2001]) are synergistic in cardiac phenotypes of CHARGE (Randall et al., 2009) and both are partially mediated through effects on p53 (Caprio \& Baldini, 2014; Van Nostrand et al., 2014). There is also an overlap of Kabuki syndrome, which is caused with pathogenic variations in lysine-specific chromatin modifiers (KMT2D, OMIM 602113 and KDM6A, OMIM 300128), which operate through the same chromatin remodeling machinery as CHD7 and can lead to CHD7-negative CHARGE syndrome (Butcher et al., 2017; Moccia et al., 2018; Sakata et al., 2017; Schulz et al., 2014). Chromatin and abnormal methylation patterning are also implicated in multifactorial causes of conotruncal defects (Radhakrishna et al., 2018). Together, these data suggest multiple common pathways in chromatin biology are necessary for neural crest cell differentiation and migration.

\section{3 | CLINICAL IMPACT OF CHARGE ON CHD OUTCOME}

Advances in congenital cardiac surgery, preoperative evaluation with catheterization, and advancing imaging have reduced mortality with surgical repair of congenital heart disease, but there remains significant morbidity and mortality associated with congenital heart disease 
(Gilboa, Salemi, Nembhard, Fixler, \& Correa, 2010). Multiple preoperative risk factors contribute to postoperative outcomes; prominent among these risk factors is extra-cardiac organ system involvement (Landis, Cooper, \& Hinton, 2016). Abnormal development of multiple organ systems is common in many genetic syndromes and associations, with cardiac development being the most common (Fahed, Gelb, Seidman, \& Seidman, 2013). As such, individuals with genetic syndromes and associations represent $20-30 \%$ of all congenital heart disease and have a higher incidence of AVSD, conotruncal defects, and aortic arch abnormalities that require surgical repair (Patel et al., 2016).

Individuals with congenital heart disease and a genetic syndrome or association have increased risk of poorer outcomes compared to nonsyndromic individuals with congenital heart disease (Alsoufi et al., 2016; Formigari et al., 2009; Landis et al., 2016; Patel et al., 2010). However, of the limited studies that dissect the effect of specific genetic syndromes and associations on outcomes after congenital heart disease repair, there are large variations in associated morbidity and mortality ranging from markedly increase risk to relative protection in surgical outcomes depending on the syndrome (Landis et al., 2016; Michielon et al., 2009). In CHARGE syndrome, the type of congenital heart defects are hemodynamically significant enough to require surgery in $63-79 \%$ of individuals with a congenital heart defect and often required multiple, staged surgical repairs (CorstenJanssen, Kerstjens-Frederikse, et al., 2013; Corsten-Janssen, Saitta, et al., 2013; Husu et al., 2013; Wyse et al., 1993). The high incidence of surgical repair, high frequency of staged repair, and multiple organ systems frequently affected in individuals with CHARGE syndrome belies the importance of understanding surgical outcomes and factors to account for in the peri-operative management of individuals of CHARGE syndrome.

The wide spectrum of congenital heart disease in individuals with CHARGE syndrome and the rarity of the disease has led to limited data that specifically isolates the impact of CHARGE on postoperative outcomes. The limited data that does exist suggests that postsurgical outcomes in individuals with CHARGE syndrome are suboptimal (Michielon et al., 2009; Wyse et al., 1993), and the highest morbidity and mortality occurs within the neonatal period (<6 months; Blake et al., 1990; Tellier et al., 1998). The few identified risks factors for increased morbidity and mortality for individuals with CHARGE are predominantly airway and feeding abnormalities (Bergman et al., 2010; Blake et al., 1990; Issekutz et al., 2005; Tellier et al., 1998; Wyse et al., 1993) but there is additional increased risk of death with congenital heart disease particularly after the neonatal period (Bergman et al., 2010; Issekutz et al., 2005). The limited outcomes data in CHARGE, however, may be insufficient to assess the impact of the other associated organ system abnormalities that occur in CHARGE syndrome.

It is important to consider the role of immunodeficiency with the aforementioned airway and gastrointestinal anomalies on postsurgical outcomes in CHARGE syndrome. With increased prevalence and available outcomes data for individuals with 22q11.2, assessing the impact of 22q11.2 DS on peri-operative outcomes can provide some insight into CHARGE syndrome given the clinical overlap of cardiac defects (i.e., conotruncal and aortic arch abnormalities), airway anomalies (i.e., cleft lip and palate), and immunodeficiencies between the two syndromes (Corsten-Janssen, Kerstjens-Frederikse, et al., 2013; Corsten-Janssen, Saitta, et al., 2013; Hsu et al., 2016; Jyonouchi et al., 2009; Randall et al., 2009; Sanka et al., 2007). Outcomes data from 22q11.2 DS suggest mildly increased perioperative morbidity and increased length of stay, but overall similar long-term outcomes compared to nonsyndromic repair of matched congenital heart disease (Alsoufi et al., 2017; McDonald et al., 2013; Mercer-Rosa, Elci, Pinto, Tanel, \& Goldmuntz, 2018; Michielon et al., 2009; Woolman et al., 2019). Part of this mild increase in perioperative morbidity and mortality in 22q11.2 DS is related to the associated immunodeficiency and increased risk of postoperative infection (Naimo et al., 2016). CHARGE and 22q11.2 DS show clinical overlap in immunodeficiency (Chopra, Baretto, Duddridge, \& Browning, 2009; Hsu et al., 2016; Jyonouchi et al., 2009; Wong et al., 2015), though immune deficits tend to be less severe in CHARGE syndrome (Hsu et al., 2016). Together, these data suggest only minor contribution of immunodeficiency to peri-operative and long-term outcomes in CHARGE syndrome.

Outcomes for individuals with CHARGE syndrome are typically significantly worse than for those with 22q11.2 DS (Michielon et al., 2009), suggesting additional factors that separate these syndromes likely influence the clinical course. There are key differences between CHARGE and 22q11.2 DS in terms of the types of airway malformations (e.g., choanal atresia, vascular rings, and tracheobronchomalacia), feeding difficulties, and involvement of cranial nerves IX and $X$ which can impart particular morbidity and mortality among CHARGE patients (K. Blake et al., 2009; Corsten-Janssen, Kerstjens-Frederikse, et al., 2013; Corsten-Janssen, Saitta, et al., 2013; Corsten-Janssen et al., 2016; Hudson, Macdonald, Friedman, \& Blake, 2017; Stack \& Wyse, 1991). In combination, these create a particularly high risk of postoperative airway events and aspiration, especially after cardiac surgery (Blake et al., 2009). Such events are a primary cause of death cited in the limited studies of postsurgical and long term outcomes in individuals with CHARGE (Bergman et al., 2010; Blake et al., 1990; Tellier et al., 1998; Wyse et al., 1993). Additionally, there is evidence that CHD7 plays a role in response to ischemia as evidence in negative regulation of angiogenesis in the peri-necrotic regions of glioblastoma (Boyd et al., 2019), which may play a role in cardiac recovery and remodeling after cardiac surgery. Therefore, pre- and postoperative management should include a focus on prevention of aspiration as a primary means of decreasing mortality in CHARGE patients, particularly after cardiac surgery.

\section{CONCLUSION}

CHARGE syndrome has widely variable phenotypes in congenital heart disease. The spectrum of congenital heart defects appears to be secondary to chromatin signaling altering the migration and development of the neural crest cell lineage and cardiac mesoderm. However 
due to the rarity of CHARGE syndrome and spectrum of pathogenic variants, understanding the full genotype-phenotype association within congenital heart disease and the other systems affected by CHARGE syndrome requires a coordinated effort to pool data across large cohort and case series studies. This effort would be enhanced by publication of descriptive datasets in supporting Information to allow for meta-analysis. Despite the wide variation in congenital heart defects in CHARGE syndrome, there is a bias toward complex congenital heart disease (e.g., conotruncal defects and AVSDs) that require major and often repeated cardiac surgical repair, which can impart considerable morbidity and mortality to individuals with CHARGE syndrome. However, poor postoperative outcomes from neonatal cardiac repair appear to be primarily driven by noncardiac risk factors. Understanding these risk factors can be critical for minimize the postoperative risk for these individuals, particularly the risk of aspiration and airway complications.

\section{ACKNOWLEDGMENTS}

DMM is funded by the Alfred A. Taubman Medical Research Institute, NIH DC R01-014456 and by the Donita B. Sullivan, MD, Research Professorship in Pediatrics. DMM also serves as Chair of the Scientific Advisory Board for the CHARGE Syndrome Foundation.

\section{ORCID}

Donna M. Martin (D) https://orcid.org/0000-0002-8070-2007

\section{REFERENCES}

Alsoufi, B., Gillespie, S., Mahle, W. T., Deshpande, S., Kogon, B., Maher, K., \& Kanter, K. (2016). The effect of noncardiac and genetic abnormalities on outcomes following neonatal congenital heart surgery. Seminars in Thoracic and Cardiovascular Surgery, 28(1), 105-114. https://doi.org/10.1053/j.semtcvs.2015.10.016

Alsoufi, B., McCracken, C., Shashidharan, S., Deshpande, S., Kanter, K., \& Kogon, B. (2017). The impact of 22q11.2 deletion syndrome on surgical repair outcomes of conotruncal cardiac anomalies. Annals of Thoracic Surgery, 104(5), 1597-1604. https://doi.org/10.1016/j.athoracsur. 2017.04.019

Aramaki, M., Udaka, T., Kosaki, R., Makita, Y., Okamoto, N., Yoshihashi, H., ... Kosaki, K. (2006). Phenotypic spectrum of CHARGE syndrome with CHD7 mutations. Journal of Pediatrics, 148(3), 410-414. https://doi. org/10.1016/j.jpeds.2005.10.044

Asad, Z., Pandey, A., Babu, A., Sun, Y., Shevade, K., Kapoor, S., ... Sachidanandan, C. (2016). Rescue of neural crest-derived phenotypes in a zebrafish CHARGE model by Sox10 downregulation. Human Molecular Genetics, 25(16), 3539-3554. https://doi.org/10.1093/hmg/ddw198

Bajpai, R., Chen, D. A., Rada-Iglesias, A., Zhang, J., Xiong, Y., Helms, J., ... Wysocka, J. (2010). CHD7 cooperates with PBAF to control multipotent neural crest formation. Nature, 463(7283), 958-962. https://doi.org/10.1038/nature08733

Bélanger, C., Bérubé-Simard, F. A., Leduc, E., Bernas, G., Campeau, P. M., Lalani, S. R., ... Pilon, N. (2018). Dysregulation of cotranscriptional alternative splicing underlies CHARGE syndrome. Proceedings of the National Academy of Sciences of the United States of America, 115(4), E620-E629. https://doi.org/10.1073/pnas.1715378115

Bergman, J. E. H., Blake, K. D., Bakker, M. K., du Marchie Sarvaas, G. J., Free, R. H., \& van Ravenswaaij-Arts, C. M. A. (2010). Death in CHARGE syndrome after the neonatal period. Clinical Genetics, 77(3), 232-240. https://doi.org/10.1111/j.1399-0004.2009.01334.x
Bergman, J. E. H., Janssen, N., Hoefsloot, L. H., Jongmans, M. C. J., Hofstra, R. M. W., \& van Ravenswaaij-Arts, C. M. A. (2011). CHD7 mutations and CHARGE syndrome: The clinical implications of an expanding phenotype. Journal of Medical Genetics, 48(5), 334-342. https://doi.org/10.1136/jmg.2010.087106

Bérubé-Simard, F.-A., \& Pilon, N. (2019). Molecular dissection of CHARGE syndrome highlights the vulnerability of neural crest cells to problems with alternative splicing and other transcription-related processes. Transcription, 10(1), 21-28. https://doi.org/10.1080/21541264.2018. 1521213

Blake, K., MacCuspie, J., Hartshorne, T. S., Roy, M., Davenport, S. L. H., \& Corsten, G. (2009). Postoperative airway events of individuals with CHARGE syndrome. International Journal of Pediatric Otorhinolaryngology, 73(2), 219-226. https://doi.org/10.1016/j.jjporl.2008.10.005

Blake, K. D., Russell-Eggitt, I. M., Morgan, D. W., Ratcliffe, J. M., \& Wyse, R. K. H. (1990). Who's in CHARGE? Multidisciplinary management of patients with CHARGE association. Archives of Disease in Childhood, 65(2), 217-223. https://doi.org/10.1136/adc.65.2.217

Blake, K. D., Davenport, S. L. H., Hall, B. D., Hefner, M. A., Pagon, R. A., Williams, M. S., ... Graham, J. M. (1998). CHARGE association: An update and review for the primary pediatrician. Clinical Pediatrics, 37 (3), 159-173. https://doi.org/10.1177/000992289803700302

Botto, L. D., Lin, A. E., Riehle-Colarusso, T., Malik, S., \& Correa, A. (2007). Seeking causes: Classifying and evaluating congenital heart defects in etiologic studies. Birth Defects Research Part A: Clinical and Molecular Teratology, 79(10), 714-727. https://doi.org/10.1002/bdra.20403

Boyd, N. H., Walker, K., Ayokanmbi, A., Gordon, E. R., Whetsel, J., Smith, C. M., ... Hjelmeland, A. B. (2019). Chromodomain helicase DNA-binding protein 7 is suppressed in the Perinecrotic/ischemic microenvironment and is a novel regulator of Glioblastoma angiogenesis. Stem Cells, 37(4), 453-462. https://doi.org/10.1002/stem.2969

Busa, T., Legendre, M., Bauge, M., Quarello, E., Bretelle, F., Bilan, F., ... Philip, N. (2016). Prenatal findings in children with early postnatal diagnosis of CHARGE syndrome. Prenatal Diagnosis, 36(6), 561-567. https://doi.org/10.1002/pd.4825

Butcher, D. T., Cytrynbaum, C., Turinsky, A. L., Siu, M. T., InbarFeigenberg, M., Mendoza-Londono, R., ... Weksberg, R. (2017). CHARGE and kabuki syndromes: Gene-specific DNA methylation signatures identify epigenetic mechanisms linking these clinically overlapping conditions. American Journal of Human Genetics, 100(5), 773-788. https://doi.org/10.1016/j.ajhg.2017.04.004

Caprio, C., \& Baldini, A. (2014). p53 suppression partially rescues the mutant phenotype in mouse models of DiGeorge syndrome. Proceedings of the National Academy of Sciences of the United States of America, 111(37), 13385-13390. https://doi.org/10.1073/pnas.1401923111

Chopra, C., Baretto, R., Duddridge, M., \& Browning, M. J. (2009). T-cell immunodeficiency in CHARGE syndrome. Acta Paediatrica (Oslo, Norway: 1992), 98(2), 408-410. https://doi.org/10.1111/j.1651-2227. 2008.01077.x

Corsten-Janssen, N., Saitta, S. C., Hoefsloot, L. H., McDonaldMcGinn, D. M., Driscoll, D. A., Derks, R., ... van RavenswaaijArts, C. M. A. (2013). More clinical overlap between 22q11.2 deletion syndrome and CHARGE syndrome than often anticipated. Molecular Syndromology, 4(5), 235-245. https://doi.org/10.1159/000351127

Corsten-Janssen, N., du Marchie Sarvaas, G. J., KerstjensFrederikse, W. S., Hoefsloot, L. H., van Beynum, I. M., Kapusta, L., \& van Ravenswaaij-Arts, C. M. A. (2014). CHD7 mutations are not a major cause of atrioventricular septal and conotruncal heart defects. American Journal of Medical Genetics, Part A, 164(12), 3003-3009. https://doi.org/10.1002/ajmg.a.36747

Corsten-Janssen, N., Kerstjens-Frederikse, W. S., Du Marchie Sarvaas, G. J., Baardman, M. E., Bakker, M. K., Bergman, J. E. H., ... Kapusta, L. (2013). The cardiac phenotype in patients with a CHD7 mutation. Circulation: Cardiovascular Genetics, 6(3), 248-254. https:// doi.org/10.1161/CIRCGENETICS.113.000054 
Corsten-Janssen, N., \& Scambler, P. J. (2017). Clinical and molecular effects of CHD7 in the heart. American Journal of Medical Genetics Part C: Seminars in Medical Genetics, 175(4), 487-495. https://doi.org/10. 1002/ajmg.c.31590

Corsten-Janssen, N., van Ravenswaaij-Arts, C. M. A., \& Kapusta, L. (2016). Congenital arch vessel anomalies in CHARGE syndrome: A frequent feature with risk for co-morbidity. International Journal of Cardiology. Heart \& Vasculature, 12, 21-25. https://doi.org/10.1016/j.ijcha.2016. 05.015

Cyran, S. E., Martinez, R., Daniels, S., Dignan, P. S. J., \& Kaplan, S. (1987). Spectrum of congenital heart disease in CHARGE association. The Journal of Pediatrics, 110(4), 576-578. https://doi.org/10.1016/ S0022-3476(87)80555-3

Fahed, A. C., Gelb, B. D., Seidman, J. G., \& Seidman, C. E. (2013). Genetics of congenital heart disease. Circulation Research, 112(4), 707-720. https://doi.org/10.1161/CIRCRESAHA.112.300853

Formigari, R., Michielon, G., Digilio, M. C., Piacentini, G., Carotti, A., Giardini, A., ... Marino, B. (2009, April). Genetic syndromes and congenital heart defects: How is surgical management affected? European Journal of Cardio-Thoracic Surgery, 35, 606-614. https://doi.org/10. 1016/j.ejcts.2008.11.005

Gennery, A. R., Slatter, M. A., Rice, J., Hoefsloot, L. H., Barge, D., McLeanTooke, A., ... Johnson, D. (2008). Mutations in CHD7 in patients with CHARGE syndrome cause T-B + natural killer cell + severe combined immune deficiency and may cause Omenn-like syndrome. Clinical and Experimental Immunology, 153(1), 75-80. https://doi.org/10.1111/j. 1365-2249.2008.03681.x

Gilboa, S. M., Salemi, J. L., Nembhard, W. N., Fixler, D. E., \& Correa, A. (2010). Mortality resulting from congenital heart disease among children and adults in the United States, 1999 to 2006. Circulation, 122 (22), 2254-2263. https://doi.org/10.1161/CIRCULATIONAHA.110. 947002

Hale, C. L., Niederriter, A. N., Green, G. E., \& Martin, D. M. (2016). Atypical phenotypes associated with pathogenic CHD7 variants and a proposal for broadening CHARGE syndrome clinical diagnostic criteria. American Journal of Medical Genetics, Part A, 170(2), 344-354. https://doi. org/10.1002/ajmg.a.37435

Hall, B. D. (1979). Choanal atresia and associated multiple anomalies. The Journal of Pediatrics, 95(3), 395-398. https://doi.org/10.1016/S00223476(79)80513-2

Hittner, H. M., Hirsch, N. J., Kreh, G. M., \& Rudolph, A. J. (1979). Colobomatous microphthalmia, heart disease, hearing loss, and mental retardation-A syndrome. Journal of Pediatric Ophthalmology and Strabismus, 16(2), 122-128 Retrieved from http://www.ncbi.nlm.nih.gov/ pubmed $/ 458518$

Hsu, P., Ma, A., Barnes, E. H., Wilson, M., Hoefsloot, L. H., Rinne, T., ... Mehr, S. (2016). The immune phenotype of patients with CHARGE syndrome. Journal of Allergy and Clinical Immunology: In Practice, 4(1), 96-103.e2. https://doi.org/10.1016/j.jaip.2015.09.004

Hudson, A., Macdonald, M., Friedman, J. N., \& Blake, K. (2017). CHARGE syndrome gastrointestinal involvement: From mouth to anus. Clinical Genetics, 92(1), 10-17. https://doi.org/10.1111/cge.12892

Husu, E., Hove, H. D., Farholt, S., Bille, M., Tranebjærg, L., Vogel, I., \& Kreiborg, S. (2013). Phenotype in 18 Danish subjects with genetically verified CHARGE syndrome. Clinical Genetics, 83(2), 125-134. https:// doi.org/10.1111/j.1399-0004.2012.01884.x

Issekutz, K. A., Graham, J. M., Prasad, C., Smith, I. M., \& Blake, K. D. (2005). An epidemiological analysis of CHARGE syndrome: Preliminary results from a Canadian study. American Journal of Medical Genetics, 133 A(3), 309-317. https://doi.org/10.1002/ajmg.a.30560

Jongmans, M. C. J., Admiraal, R. J., Van Der Donk, K. P., Vissers, L. E. L. M., Baas, A. F., Kapusta, L., ... Van Ravenswaaij, C. M. A. (2006). CHARGE syndrome: The phenotypic spectrum of mutations in the CHD7 gene. Journal of Medical Genetics, 43(4), 306-314. https://doi.org/10.1136/ jmg.2005.036061
Jongmans, M. C. J., Hoefsloot, L. H., van der Donk, K. P., Admiraal, R. J., Magee, A., van de Laar, I., ... van Ravenswaaij, C. M. A. (2008). Familial CHARGE syndrome and the CHD7 gene: $A$ recurrent missense mutation, intrafamilial recurrence and variability. American Journal of Medical Genetics. Part A, 146A(1), 43-50. https://doi.org/10.1002/ajmg.a. 31921

Jyonouchi, S., McDonald-McGinn, D. M., Bale, S., Zackai, E. H., \& Sullivan, K. E. (2009). CHARGE syndrome and chromosome 22q11.2 deletion syndrome: A comparison of immunologic and nonimmunologic phenotypic features. Pediatrics, 123, e871-e877. https://doi.org/10.1542/peds.2008-3400

Lalani, S. R., Safiullah, A. M., Molinari, L. M., Fernbach, S. D., Martin, D. M., \& Belmont, J. W. (2004). SEMA3E mutation in a patient with CHARGE syndrome. Journal of Medical Genetics, 41(7), e94-e94. https://doi.org/10.1136/jmg.2003.017640

Lalani, S. R., Safiullah, A. M., Fernbach, S. D., Harutyunyan, K. C., Thaller, C., Peterson, L. E., ... Belmont, J. W. (2006). Spectrum of CHD7 mutations in 110 individuals with CHARGE syndrome and genotype-phenotype correlation. American Journal of Human Genetics, 78(2), 303-314. https://doi.org/10.1086/500273

Landis, B. J., Cooper, D. S., \& Hinton, R. B. (2016). CHD associated with syndromic diagnoses: Peri-operative risk factors and early outcomes. Cardiology in the Young, 26(1), 30-52. https://doi.org/10.1017/ S1047951115001389

Legendre, M., Abadie, V., Attié-Bitach, T., Philip, N., Busa, T., Bonneau, D., ... Gilbert-Dussardier, B. (2017). Phenotype and genotype analysis of a French cohort of 119 patients with CHARGE syndrome. American Journal of Medical Genetics, Part C: Seminars in Medical Genetics, 175 (4), 417-430. https://doi.org/10.1002/ajmg.c.31591

Legendre, M., Gonzales, M., Goudefroye, G., Bilan, F., Parisot, P., Perez, M.-J., ... Attié-Bitach, T. (2012). Antenatal spectrum of CHARGE syndrome in 40 fetuses with CHD7 mutations. Journal of Medical Genetics, 49(11), 698-707. https://doi.org/10.1136/jmedgenet-2012100926

Lin, A. E., Chin, A. J., Devine, W., Park, S. C., \& Zackai, E. (1987). The pattern of cardiovascular malformation in the Charge association. American Journal of Diseases of Children, 141(9), 1010-1013. https://doi. org/10.1001/archpedi.1987.04460090087034

Lindsay, E. A., Vitelli, F., Su, H., Morishima, M., Huynh, T., Pramparo, T., ... Baldini, A. (2001). Tbx1 haploinsufficieny in the DiGeorge syndrome region causes aortic arch defects in mice. Nature, 410(6824), 97-101. https://doi.org/10.1038/35065105

Liu, Y., Chen, S., Zühlke, L., Black, G. C., Choy, M. K., Li, N., \& Keavney, B. D. (2019). Global birth prevalence of congenital heart defects 1970-2017: Updated systematic review and meta-analysis of 260 studies. International Journal of Epidemiology, 48(2), 455-463. https://doi.org/10.1093/ije/dyz009

Liu, Z.-Z., Guo, J., Lu, Y., Liu, W., Fu, X., Yao, T., ... Xu, H. A. (2019). Sema3E is required for migration of cranial neural crest cells in zebrafish: Implications for the pathogenesis of CHARGE syndrome. International Journal of Experimental Pathology, 100, 234-243. https://doi.org/10.1111/ iep.12331

McDonald, R., Dodgen, A., Goyal, S., Gossett, J. M., Shinkawa, T., Uppu, S. C., ... Gupta, P. (2013). Impact of 22q11.2 deletion on the postoperative course of children after cardiac surgery. Pediatric Cardiology, 34(2), 341-347. https://doi.org/10.1007/s00246-012-0454-x

Mercer-Rosa, L., Elci, O. U., Pinto, N. M., Tanel, R. E., \& Goldmuntz, E. (2018). 22q11.2 deletion status and perioperative outcomes for tetralogy of Fallot with pulmonary atresia and multiple Aortopulmonary collateral vessels. Pediatric Cardiology, 39(5), 906-910. https://doi.org/ 10.1007/s00246-018-1840-9

Merscher, S., Funke, B., Epstein, J. A., Heyer, J., Puech, A., Lu, M. M., ... Kucherlapati, R. (2001). TBX1 is responsible for cardiovascular defects in velo-cardio-facial/DiGeorge syndrome. Cell, 104(4), 619-629. https://doi.org/10.1016/s0092-8674(01)00247-1 
Michielon, G., Marino, B., Oricchio, G., Digilio, M. C., lorio, F., Filippelli, S., ... Di Donato, R. M. (2009). Impact of DEL22q11, trisomy 21, and other genetic syndromes on surgical outcome of conotruncal heart defects. Journal of Thoracic and Cardiovascular Surgery, 138(3), 565-570. https://doi.org/10.1016/j.jtcvs.2009.03.009

Moccia, A., Srivastava, A., Skidmore, J. M., Bernat, J. A., Wheeler, M., Chong, J. X., ... Bielas, S. L. (2018). Genetic analysis of CHARGE syndrome identifies overlapping molecular biology. Genetics in Medicine, 20(9), 1022-1029. https://doi.org/10.1038/gim.2017.233

Naimo, P. S., Fricke, T. A., Yong, M. S., D'Udekem, Y., Kelly, A., Radford, D. J., ... Konstantinov, I. E. (2016). Outcomes of Truncus Arteriosus repair in children: 35 years of experience from a single institution. Seminars in Thoracic and Cardiovascular Surgery, 28(2), 500-511. https://doi.org/10.1053/j.semtcvs.2015.08.009

Oley, C. A., Baraitser, M., \& Grant, D. B. (1988). A reappraisal of the CHARGE association. Journal of Medical Genetics, 25(3), 147-156. https://doi.org/10.1136/jmg.25.3.147

Pagon, R. A., Graham, J. M., Zonana, J., \& Yong, S. L. (1981). Coloboma, congenital heart disease, and choanal atresia with multiple anomalies: CHARGE association. The Journal of Pediatrics, 99(2), 223-227. https://doi.org/10.1016/S0022-3476(81)80454-4

Patel, A., Costello, J. M., Backer, C. L., Pasquali, S. K., Hill, K. D., Wallace, A. S., ... Jacobs, M. L. (2016). Prevalence of noncardiac and genetic abnormalities in neonates undergoing cardiac operations: Analysis of the Society of Thoracic Surgeons congenital heart surgery database. Annals of Thoracic Surgery, 102(5), 1607-1614. https://doi. org/10.1016/j.athoracsur.2016.04.008

Patel, A., Hickey, E., Mavroudis, C., Jacobs, J. P., Jacobs, M. L., Backer, C. L., ... Mavroudis, C. D. (2010). Impact of noncardiac congenital and genetic abnormalities on outcomes in Hypoplastic left heart syndrome. Annals of Thoracic Surgery, 89(6), 1805-1814. https://doi. org/10.1016/j.athoracsur.2010.02.004

Pauli, S., Bajpai, R., \& Borchers, A. (2017, December 1). CHARGEd with neural crest defects. American Journal of Medical Genetics, Part C: Seminars in Medical Genetics, 175, 478-486. https://doi.org/10.1002/ajmg.c.31584

Payne, S., Burney, M. J., McCue, K., Popal, N., Davidson, S. M., Anderson, R. H., \& Scambler, P. J. (2015). A critical role for the chromatin remodeller $\mathrm{CHD7}$ in anterior mesoderm during cardiovascular development. Developmental Biology, 405(1), 82-95. https://doi.org/ 10.1016/j.ydbio.2015.06.017

Plein, A., Fantin, A., \& Ruhrberg, C. (2015). Neural crest cells in cardiovascular development. Current Topics in Developmental Biology, 111, 183-200. https://doi.org/10.1016/bs.ctdb.2014.11.006

Radhakrishna, U., Vishweswaraiah, S., Veerappa, A. M., Zafra, R., Albayrak, S., Sitharam, P. H., ... Bahado-Singh, R. (2018). Newborn blood DNA epigenetic variations and signaling pathway genes associated with tetralogy of Fallot (TOF). PLoS One, 13(9), e0203893. https://doi.org/10.1371/journal.pone.0203893

Randall, V., McCue, K., Roberts, C., Kyriakopoulou, V., Beddow, S., Barrett, A. N., ... Scambler, P. J. (2009). Great vessel development requires biallelic expression of Chd7 and Tbx1 in pharyngeal ectoderm in mice. Journal of Clinical Investigation, 119(11), 3301-3310. https:// doi.org/10.1172/JCl37561

Sakata, S., Okada, S., Aoyama, K., Hara, K., Tani, C., Kagawa, R., ... Kobayashi, M. (2017). Individual clinically diagnosed with CHARGE syndrome but with a mutation in KMT2D, a gene associated with kabuki syndrome: A case report. Frontiers in Genetics, 8. https://doi. org/10.3389/fgene.2017.00210

Sanka, M., Tangsinmankong, N., Loscalzo, M., Sleasman, J. W., \& Dorsey, M. J. (2007). Complete DiGeorge syndrome associated with CHD7 mutation. The Journal of Allergy and Clinical Immunology, 120(4), 952-954. https://doi.org/10.1016/j.jaci.2007.08.013

Sanlaville, D., \& Verloes, A. (2007). CHARGE syndrome: An update. European Journal of Human Genetics: EJHG, 15(4), 389-399. https:// doi.org/10.1038/sj.ejhg.5201778
Schnetz, M. P., Bartels, C. F., Shastri, K., Balasubramanian, D., Zentner, G. E., Balaji, R., ... Scacheri, P. C. (2009). Genomic distribution of $\mathrm{CHD7}$ on chromatin tracks H3K4 methylation patterns. Genome Research, 19(4), 590-601. https://doi.org/10.1101/gr.086983.108

Schulz, Y., Freese, L., Mänz, J., Zoll, B., Völter, C., Brockmann, K., ... Pauli, S. (2014). CHARGE and kabuki syndromes: A phenotypic and molecular link. Human Molecular Genetics, 23(16), 4396-4405. https:// doi.org/10.1093/hmg/ddu156

Schulz, Y., Wehner, P., Opitz, L., Salinas-Riester, G., Bongers, E. M. H. F., Van Ravenswaaij-Arts, C. M. A., ... Pauli, S. (2014). CHD7, the gene mutated in CHARGE syndrome, regulates genes involved in neural crest cell guidance. Human Genetics, 133(8), 997-1009. https://doi. org/10.1007/s00439-014-1444-2

Siebert, J. R., Graham, J. M., \& MacDonald, C. (1985). Pathologic features of the CHARGE association: Support for involvement of the neural crest. Teratology, 31(3), 331-336. https://doi.org/10.1002/tera. 1420310303

Stack, C. G., \& Wyse, R. K. H. (1991). Incidence and management of airway problems in the CHARGE association. Anaesthesia, 46, 582-585. https://doi.org/10.1111/j.1365-2044.1991.tb09664.x

Stoller, J. Z., \& Epstein, J. A. (2005). Cardiac neural crest. Seminars in Cell \& Developmental Biology, 16(6), 704-715. https://doi.org/10.1016/j. semcdb.2005.06.004

Strömland, K., Sjögreen, L., Johansson, M., Joelsson, B. M. E., Miller, M., Danielsson, S., ... Granström, G. (2005). CHARGE association in Sweden: Malformations and functional deficits. American Journal of Medical Genetics, 133 A(3), 331-339. https://doi.org/10.1002/ajmg.a.30563

Tellier, A. L., Cormier-Daire, V., Abadie, V., Amiel, J., Sigaudy, S., Bonnet, D., ... Lyonnet, S. (1998). CHARGE syndrome: Report of 47 cases and review. American Journal of Medical Genetics, 76(5), 402-409. https://doi.org/10.1002/(SICI)1096-8628(19980413)76: 5<402::AID-AJMG7>3.0.CO;2-O

Ufartes, R., Schwenty-Lara, J., Freese, L., Neuhofer, C., Möller, J., Wehner, P., ... Pauli, S. (2018). Sema3a plays a role in the pathogenesis of CHARGE syndrome. Human Molecular Genetics, 27(8), 1343-1352. https://doi.org/10.1093/hmg/ddy045

Van Nostrand, J. L., Brady, C. A., Jung, H., Fuentes, D. R., Kozak, M. M., Johnson, T. M., ... Attardi, L. D. (2014). Inappropriate p53 activation during development induces features of CHARGE syndrome. Nature, 514(7521), 228-232. https://doi.org/10.1038/nature13585

Verloes, A. (2005). Updated diagnostic criteria for CHARGE syndrome: A proposal. American Journal of Medical Genetics Part A, 133A(3), 306-308. https://doi.org/10.1002/ajmg.a.30559

Verzi, M. P., McCulley, D. J., De Val, S., Dodou, E., \& Black, B. L. (2005). The right ventricle, outflow tract, and ventricular septum comprise a restricted expression domain within the secondary/anterior heart field. Developmental Biology, 287(1), 134-145. https://doi.org/10.1016/j. ydbio.2005.08.041

Vissers, L. E. L. M., van Ravenswaaij, C. M. A., Admiraal, R., Hurst, J. A., de Vries, B. B. A., Janssen, I. M., ... van Kessel, A. G. (2004). Mutations in a new member of the chromodomain gene family cause CHARGE syndrome. Nature Genetics, 36(9), 955-957. https://doi.org/10.1038/ ng1407

Wincent, J., Holmberg, E., Strömland, K., Soller, M., Mirzaei, L., Djureinovic, T., ... Schoumans, J. (2008). CHD7 mutation spectrum in 28 Swedish patients diagnosed with CHARGE syndrome. Clinical Genetics, 74(1), 31-38. https://doi.org/10.1111/j.1399-0004.2008. 01014.x

Wong, M. T. Y., Lambeck, A. J. A., Van Der Burg, M., La Bastide-Van Gemert, S., Hogendorf, L. A., Van Ravenswaaij-Arts, C. M. A., \& Schölvinck, E. H. (2015). Immune dysfunction in children with CHARGE syndrome: A cross-sectional study. PLOS ONE, 10(11), e0142350. https://doi.org/10.1371/journal.pone.0142350

Woolman, P., Bearl, D. W., Soslow, J. H., Dodd, D. A., Thurm, C., Hall, M., ... Godown, J. (2019). Characteristics and outcomes of heart 
transplantation in DiGeorge syndrome. Pediatric Cardiology, 40(4), 768-775. https://doi.org/10.1007/s00246-019-02063-w

Wyse, R. K. H., Al-Mahdawi, S., Burn, J., \& Blake, K. (1993). Congenital heart disease in CHARGE association. Pediatric Cardiology, 14(2), 75-81. https://doi.org/10.1007/BF00796983

Zentner, G. E., Layman, W. S., Martin, D. M., \& Scacheri, P. C. (2010) Molecular and phenotypic aspects of CHD7 mutation in CHARGE syndrome. American Journal of Medical Genetics Part A, 152A(3), 674-686. https://doi.org/10.1002/ajmg.a.33323
How to cite this article: Meisner JK, Martin DM. Congenital heart defects in CHARGE: The molecular role of CHD7 and effects on cardiac phenotype and clinical outcomes. Am J Med Genet Part C. 2020;184C:81-89. https://doi.org/10.1002/ ajmg.c.31761 